\title{
Gérald Bronner, La pensée extrême. Comment des hommes ordinaires deviennent des fanatiques
}

Paris, Denoël, 2009, 348 p.

Jean-Bruno Renard

\section{OpenEdition}

\section{Journals}

Édition électronique

URL : http://journals.openedition.org/assr/23456

DOI : 10.4000 /assr.23456

ISSN : $1777-5825$

Éditeur

Éditions de l'EHESS

Édition imprimée

Date de publication : 31 décembre 2011

Pagination : 133

ISBN : 9782713223273

ISSN : 0335-5985

\section{Référence électronique}

Jean-Bruno Renard, « Gérald Bronner, La pensée extrême. Comment des hommes ordinaires deviennent des fanatiques », Archives de sciences sociales des religions [En ligne], 156 | octobredécembre 2011, document 156-27, mis en ligne le 14 février 2012, consulté le 10 décembre 2020. URL : http://journals.openedition.org/assr/23456 ; DOI : https://doi.org/10.4000/assr.23456

Ce document a été généré automatiquement le 10 décembre 2020.

(c) Archives de sciences sociales des religions 


\section{Gérald Bronner, La pensée extrême. Comment des hommes ordinaires deviennent des fanatiques}

Paris, Denoël, 2009, 348 p.

Jean-Bruno Renard

\section{RÉFÉRENCE}

Gérald Bronner, La pensée extrême. Comment des hommes ordinaires deviennent des fanatiques, Paris, Denoël, 2009, 348 p.

1 La publication par Gérald Bronner de L'empire des croyances (Paris, PUF, 2003), puis de Vie et mort des croyances collectives (Paris, Hermann, 2006) a fait de son auteur une figure marquante de la "sociologie cognitive" qui s'est développée dans le sillage de la théorie générale de la rationalité de Raymond Boudon. La pensée extrême relève le défi d'appliquer cette approche à des croyances de fanatiques, que l'on qualifie si aisément de « fous » tant leurs idées et leurs comportements nous paraissent « irrationnels ». Ce livre passionnant, où l'auteur cisèle les notions comme un orfèvre, est une magistrale démonstration des mécanismes qui conduisent, de manière logique bien qu'effrayante, à adhérer à des idées extrémistes.

2 L'auteur rappelle qu'une croyance se définit à la fois par un contenu (une idée) et par un rapport à ce contenu (une adhésion plus ou moins forte). La spécificité de la pensée extrême est qu'elle " adhère radicalement à une idée radicale » (p. 130). La conséquence en est que les idées extrêmes sont soit faiblement "transsubjectives", c'est-à-dire qu'elles se propagent peu dans une population parce qu'elles sont perçues comme peu convaincantes, soit " sociopathiques ", c'est-à-dire qu'elles n'admettent pas des visions du monde différentes, soit encore dans les formes les plus dangereuses, elles cumulent les deux caractéristiques. D'où trois types d'extrémistes selon une progression croissante: les extrémistes aux croyances faiblement transsubjectives et faiblement 
sociopathiques (par exemple les collectionneurs compulsifs, les passionnés d'ovni, les fondamentalistes religieux non expansionnistes qui par conviction peuvent mettre en jeu leur vie mais pas celle des autres), les extrémistes aux croyances transsubjectives et sociopathiques (les mouvements violents, mais "compréhensibles» par beaucoup, comme les rebelles extrémistes, les égalitaristes, les antispécistes, etc.), enfin les extrémistes aux croyances faiblement transsubjectives et fortement sociopathiques (les membres de sectes se suicidant collectivement, les terroristes kamikazes, violents et « incompréhensibles »).

3 La radicalité de la pensée extrême est le point ultime - rarement atteint - d'un processus graduel et rationnel d'adhésion à des idées. "Chaque étape a poussé l'individu vers la pensée extrême, mais chacune d'entre elles, prise séparément, peut sans doute être considérée comme raisonnable»(p.36). Ainsi le militant sioniste extrémiste qui assassina Yitzhak Rabin, en 1995, a tenu un raisonnement implacable par sa logique : le juif pieux se soumet à la volonté divine; la volonté divine s'exprime dans la Torah ; selon la Torah, Dieu a donné aux juifs la Terre sainte ; toute personne qui s'oppose à la colonisation s'oppose à la volonté de Dieu et doit donc être combattue, y compris par la violence, justifiée par la Torah. De même, les terroristes islamistes d'al-Qaïda pensent que les musulmans sont persécutés par des ennemis, que le Coran incite les bons musulmans à mener contre eux une guerre sainte, que les ennemis sont les Américains et leurs alliés (et non seulement leurs gouvernants), et que par conséquent la violence envers les populations américaine ou européennes est légitime. Pour la pensée extrême, tout compromis, tout aménagement, est inacceptable. La pensée ordinaire accepte les contradictions entre les croyances qui coexistent dans notre esprit ou dans notre société. La pensée extrême ne les accepte pas et construit une doctrine cohérente, "pure ", monolithique et manichéenne. L'auteur rappelle, à la suite de plusieurs auteurs, que les terroristes ne sont pas des fous, des ignorants ou des déshérités : ils sont le plus souvent issus de classes supérieures et possèdent un niveau élevé d'instruction.

4 Nous avons, souligne-t-il, de « bonnes raisons » pour résister à l'idée d'une rationalité des comportements extrêmes : comprendre, ce serait être complice, ou admettre que le mal est en nous, ou prôner un relativisme conduisant à reconnaître les « valeurs » des terroristes. Il nous faut pourtant accepter l'idée que l'extrémisme satisfait aux critères de la rationalité : «il énonce des doctrines cohérentes»(p.61) et «il propose des moyens en adéquation aux fins poursuivies » (idem). Comme l'écrit l'auteur, « c'est là le problème avec l'extrémiste, il met en demeure par ses actions, par ses reproches, les individus plus tièdes que lui, mais partageant les mêmes valeurs, les mêmes croyances, de se mettre en conformité avec elles" (p.95). La pensée extrême pèche non par manque mais par excès de logique. En adoptant une maxime qu'ils partagent tous, «la fin justifie les moyens ", les fanatiques établissent une hiérarchie absolue et intangible de leurs valeurs. "Ce n'est pas qu'ils méconnaissent le mal, c'est qu'ils se croient autorisés à le faire » (p.269). Dans la pensée ordinaire, on «met en balance » nos valeurs selon les situations, par exemple on peut mentir pour sauver une vie, manger un aliment interdit par la religion pour survivre. Autrement dit, on fait un usage relatif et conditionnel des valeurs. Au contraire, les fanatiques adhèrent de manière inconditionnelle à certaines croyances, ce qui les conduit à une « incommensurabilité mentale ", c'est-à-dire une insensibilité à tout système de valeurs concurrent. En bref, 
les extrémistes considèrent "comme non négociables des croyances qui ne peuvent constituer le ciment de la vie sociale » (p. 307).

5 Ce n'est pas le moindre des intérêts de cet ouvrage que de s'interroger en conclusion sur la manière de «faire changer d'avis un extrémiste»(p.309). Pour l'auteur, l'attitude fanatique, pour extrême qu'elle soit, n'en est pas moins fragile et souvent temporaire : on ne nait pas fanatique, on le devient, et on ne reste pas fanatique toute sa vie ( $c f$. la bande à Baader, les Brigades rouges). Les chemins qui mènent à l'extrémisme peuvent donc être pris en sens inverse : apparition du doute - d'abord sur les éléments périphériques des croyances, ceux qui ont souvent permis la radicalisation-, rétablissement d'une "concurrence cognitive» entre les valeurs, rétablissement d'un contact social pour contrer l'enfermement sectaire, disparition des frustrations qui ont suscité l'adhésion fanatique. C'est dire combien l'ouvrage de Gérald Bronner sera précieux pour tous ceux qui s'intéressent non seulement aux croyances en général, mais plus spécialement à l'extrémisme religieux ou politique et aux dérives sectaires. 